\title{
Vegetation Greening offsets Urbanization Induced Fast Warming in Guangdong, Hong Kong, and Macao region (GHMR)
}

Liya Chao ${ }^{1 \#}$, Qingxiang Li $^{1 \# *}$, Wenjie Dong ${ }^{1 \#}$, Yuanjian Yang ${ }^{2}$, Ziyou Guo $^{1}$, Boyin Huang ${ }^{3}$, Liming Zhou ${ }^{4}$, Zhihong Jiang ${ }^{2}$, Panmao Zhai ${ }^{5}$, Phil Jones ${ }^{6}$

${ }^{1}$ School of Atmospheric Sciences and Key Laboratory of Tropical Atmosphere-Ocean System, Ministry ofEducation, SUN YatSen University, Zhuhai, China

${ }^{2}$ School of Atmospheric Sciences, Nanjing University of Information Science \& Technology, Nanjing, China

${ }^{3}$ National Centers for Environmental Information, NOAA, Asheville, USA

${ }^{4}$ Department of Atmospheric and Environmental Sciences, University at Albany, State University of New York (SUNY), Albany, NY 12222, USA

${ }^{5}$ Chinese Academy of Meteorological Sciences, CMA, Beijing, China

${ }^{6}$ Climatic Research Unit, School of Environmental Sciences, University of East Anglia, Norwich, UK

\# Southern Laboratory of Ocean Science and Engineering (Guangdong Zhuhai), Zhuhai, China.

Corresponding author: Qingxiang Li (liqingx5@mail.sysu.edu.cn)

\section{Key Points:}

- The effect of urbanization on the surface air temperature (SAT) decreases over time as regional vegetation greening increases.

- The urbanization effect on the land surface temperatures (LST) from the long time series of satellite retrievals remains significant.

- The anthropogenic heat was found to have a limited influence on SAT, but more significant and tangible effects on LST.

\begin{abstract}
Previous studies show that the environment in the Guangdong, Hong Kong, and Macao region (GHMR) is under the double stress of global warming and urbanization. Here we show that due to the increase of regional greenness, the effect of urbanization warming on surface air temperature (SAT) decreased with time and became statistically insignificant from 2004 to 2018, compared to 1979 onward; while the urbanization itself has significantly warmed land surface temperature (LST), with a warming rate of $0.14 \pm 0.04{ }^{\circ} \mathrm{C} / 10 \mathrm{a}$ at daytime and $0.02 \pm 0.02{ }^{\circ} \mathrm{C} 10 \mathrm{a}$ at nighttime during $2004-2018$, respectively. The anthropogenic heat was found to have a
\end{abstract}

This article has been accepted for publication and undergone full peer review but has not been through the copyediting, typesetting, pagination and proofreading process, which may lead to differences between this version and the Version of Record. Please cite this article as doi: 10.1029/2021GL095217.

This article is protected by copyright. All rights reserved. 
limited influence on SAT, but more significant and tangible effects on LST. It is essential to improve the control of additional warming effects caused by urbanization.

\section{Plain Language Summary}

The Guangdong, Hong Kong, and Macao region is the most economically developed region in China, and the urbanization impact on the regional warming is frequently discussed during recent decades. We found that the urbanization warming on surface air temperature (SAT) has decreased to insignificant during the recent decade due to regional greening, while the warming of land surface temperature (LST) remains tangible. This result is related to the different effects of two moderating drivers (anthropogenic heat and vegetation index) on both SAT and LST. Thus it is essential to increase urban greenness and reduce anthropogenic heat fluxes in parallel.

\section{Introduction}

The impact of urbanization has always been one of the main foci for studies on climate and climate change (Hartmann et al., 2013; Oke et al., 2017). Although there are still some differences in research data, metadata classifications, and research methods (Peterson et al., 2003; Li et al ., 2009; Qian, 2015; Wang et al., 2015; Li et al., 2017), it is believed that urbanization has a relatively small impact on the average surface air temperature (SAT) at the global scale or at a national scale for China (Wang et al., 2015; Jones et al., 1990; Li et al., 2004a; Parker et al., 2004; Li et al., 2020a). However, urbanization has significant influences at regional scale or over typical urban agglomerations in some parts of China (Jones et al., 2008; Yan et al., 2009; Yang et al., 2011; Li et al., 2014; Qian, 2015; Chao et al., 2020). Recently, more scientists began to use satellite retrieved land surface temperature (LST) data to study the urbanization impacts on ground temperature (Rao et al., 1972; Roth et al., 1989; Gallo et al., 1993). They presented strong evidence of such impacts over individual cities and economically developed agglomerations (Peng et al., 2012; Zhao et al., 2014; Yao et al., 2017; Rao et al., 2019), and correlated the impacts with local climatic conditions, economic development, city design and city scale (Watkins et al., 2007; Manoli et al., 2019). The effect of urbanization warming on SAT and LST have been studied from a range of aspects (Streutker et al., 2002; Schwarz et al., 2011; Wang et al., 2017), separately, but rarely collectively and at the inter-decadal scale due to the limited length of satellite data.

The Guangdong, Hong Kong, and Macao region (GHMR) is a typical monsoon climatic region of the tropical and subtropical transition in South China. It is also the region with the highest level of economic

This article is protected by copyright. All rights reserved. 
development in China. Due to the small regional size of Hong Kong and Macao, their urbanization level is not representative over the whole region (Chao et al., 2020), and in consideration of their particular characteristics of their observations without compromising the regional representation, we chose the entire GHMR as the study region, but the Hong Kong and Macao stations were not used. We mainly tend to answer three questions: 1) What are the similarities and differences between urbanization warming for surface and ground temperature? 2) What are the main drivers of regional warming from urbanization, and 3) the proportional contribution of each?

\section{Materials and Methods}

\subsection{Regions and SAT/ LST Data}

The study area of this paper is the Guangdong, Hong Kong, and Macao Greater Bay Area of China (Fig. 1a), and the station observations used are 86 fixed-observation meteorological stations (including national basic, benchmark, and general climate stations) from summer (June-August) 2004-2018. The observed SAT data include monthly averages of daily mean maximum temperature (Tmax), minimum temperature (Tmin), precipitation (PRE), and sunshine hours (SSD) (see Text S1 in the Supporting Information (SI)). For LST data, we use the MODIS (MYD11A2) SIN grid version 6 product based on quality control flags, which has a spatial resolution of 1000 meters and is provided every 8 days (see Text S2 and S3 in the SI).

\subsection{Quantitative method of urbanization}

For the urban and rural site division of surface air temperature, the station data were divided into 44 urban stations and 42 rural stations, using the method of Chao et al (2020), in which the night-light remote sensing data and land use data were used (see Texts S4 and S5 in the SI). At the same time, this study also refers to the calculation method of average regional series (Li et al., 2004a; Li et al., 2004b; Chao et al., 2020), which is conducive to reducing the influence of sampling bias and removing the deviation caused by individual stations with data quality problems.

For the urban and rural area division of LST, we used anthropogenic heat flux as the main basis for classifying LST in urban and rural areas(see Text S6 and S7 in the SI). The land use and nighttime light remote sensing data were combined as a secondary reference. Because the cities cause a complex series of changes in the interaction "land surface-atmosphere" that affect radiative and thermal processes in urban areas and their surroundings. As the main factor for forming surface urban heat islands, anthropogenic heat flux (AHF) is one

This article is protected by copyright. All rights reserved. 
of the key factors when evaluating and analyzing surface urban heat islands (Zhao et al., 2014). Chen et al (2019) applied the CAM5 model and found that AHF can increase the global annual average surface temperature by $0.02 \pm 0.01 \mathrm{~K}$. In addition, we considered the influence of tree canopy and elevation on LST and filtered the LST in the pixels from the forest and high mountains (Huang et al., 2017). However, according to the experimental results, this screening did not affect our conclusions, so the data used in the subsequent study were the unscreened surface temperature data (see Text S8, S9 and Table S1 in the SI).

\subsection{Drivers Analysis Methods}

Before driving factor analysis, the stations are matched with remote sensing data. According to previous studies, the underlying surface and surrounding thermal environment of the station buffer zone have a significant impact on the temperature, especially under the effect of turbulence and advection; The maximum scope of the influence of the surrounding environment on the observed records of meteorological stations does not exceed $5 \mathrm{~km}$ (Ren et al., 2011; Yang et al., 2013; Li et al., 2015). Therefore, the buffer zone of $5 \mathrm{~km}$ around the weather station is considered the critical area affecting the data quality. The data matching steps in this study are as follows: (1) first, establish a buffer zone with a radius of $5 \mathrm{~km}$ centered on the station, and (2) extract raster data (LST, Normalized Difference Vegetation Index (NDVI)/Enhanced Vegetation Index (EVI), AHF) based on the $5 \mathrm{~km}$ buffer zone of the station.

For the driving factor analysis method of mean SAT and LST for GHMR, we used SAT (mean Tmax and Tmin) as dependent variables, and daytime and nighttime LST (LST_d, LST_n), digital elevation model (DEM), SSD, PRE, EVI and AHF as independent variables to model partial least squares regression (PLSR) (see Texts S10, S11 and Figures S1, S2 in the SI). It showed a good performance in distinguishing the different independent contributions of multiple correlated factors (such as EVI and AHF, LST_d and mean Tmax, etc., see Table S2 in the SI), with the results broadly agreeing with those by the Random Forest (RF) (see Texts S12 and Table S3 in the SI). Further, PLSR can also provide significance level tests for driving factor analysis in climate change (Li, 2020b; Qian et al., 2021).

\section{Results}

\subsection{Analysis of the SAT /LST warming due to urbanization}

Chao et al. (2020) have systematically analyzed the impact of urbanization on GMHR's SAT and showed that the contribution rate (see Table S4 in the SI) of urbanization is about $11.3 \%$ (reaching the 5\% significance level),

This article is protected by copyright. All rights reserved. 
to the GMHR mean SAT warming, $6.6 \%$ to the average maximum SAT ( $\left.T_{\max }\right)$ (but statistically insignificant), and $12.9 \%$ to the mean minimum SAT $\left(T_{\min }\right)$ (significantly significant) from 1979 to 2018. Comparisons indicated that the contribution of urbanization to the GMHR warming is most prominent in summer (reaching $15.7 \%$ average highest) 23.4\% (average lowest) (see Table S4 in the SI). With the same methods, this study finds that for the period 2004-2018 (Fig. 1b-c), the urbanization impacts do not reach the 5\% significance level $\left(0.00 \pm 0.08^{\circ} \mathrm{C} / 10 \mathrm{a}\right.$ for mean $T_{\max }$, and $0.07 \pm 0.10^{\circ} \mathrm{C} / 10 \mathrm{a}$ for mean $T_{\min }$, respectively) (Fig. $1 f$ ). Besides summer, only the autumn (SON) mean $T_{\max }$ and $T_{\min }$ see significant impacts (at the $5 \%$ level), but the overall trends during this period are both negative showings no statistical importance for urbanization effects. This implies that the impact of urbanization on summer (JJA) SAT warming in GHMR changed significantly, from a significant acceleration of summer SAT warming in 1979-2018 and 1979-2003 (during this period, the urbanization warming are $0.105 \pm 0.04,0.084 \pm 0.03{ }^{\circ} \mathrm{C} / 10 \mathrm{a}$ for summer $T_{\max }$ and $T_{\min }$, respectively) to an insignificant effect in 2004-2018 (see Table S5 and Figure S3 in the SI).

AHF is attributed to the consumption of all energy sources (including fossil energy and clean energy, see Texts $\mathrm{S} 6$ in the SI). According to our estimation, this energy is about $0.03 \mathrm{~W} / \mathrm{m}^{2}$ as a global average, accounting for $0.015 \%$ of the total solar radiation (Chaisson et al., 2008), which is negligible compared to other climate factors. Meanwhile, AHF is closely related to the change of built-up areas around weather stations (Yang et al., 2020). Therefore, AHF contains both anthropogenic emission effects and land use change effects related to surface heat fluxes (Chen et al., 2020a; Jiang et al., 2019) and thus can be regarded as heat emissions caused solely by humans in urban activities (Chen et al., 2016). Therefore, it can be used to distinguish the degree of urbanization impacts to a certain extent, from the global scale warming caused by increasing greenhouse gases (Yang et al., 2020; Chen et al., 2016). In order to compare the impacts of urbanization on SAT and LST, we calculated the impact of urbanization on LST (daytime and nighttime) and SAT for the same period (2004-2018) (LST is retrieved by satellite, see Text S2 in the SI) (Fig.1d-e). The warming trend of LST is statistically significant at the $5 \%$ level, reaching $0.14 \pm 0.04^{\circ} \mathrm{C} / 10 \mathrm{a}$ at daytime due to solar heating and rapid surface warming of urban concrete pavement (although the average daytime LST in the whole GMHR shows a slightly insignificant cooling trend). The nighttime LST is also statistically significant at reaching about $0.02 \pm 0.02^{\circ} \mathrm{C}$ /10a (Fig. $1 f$, see Table S1 and Figure S4 in the SI).

This article is protected by copyright. All rights reserved. 

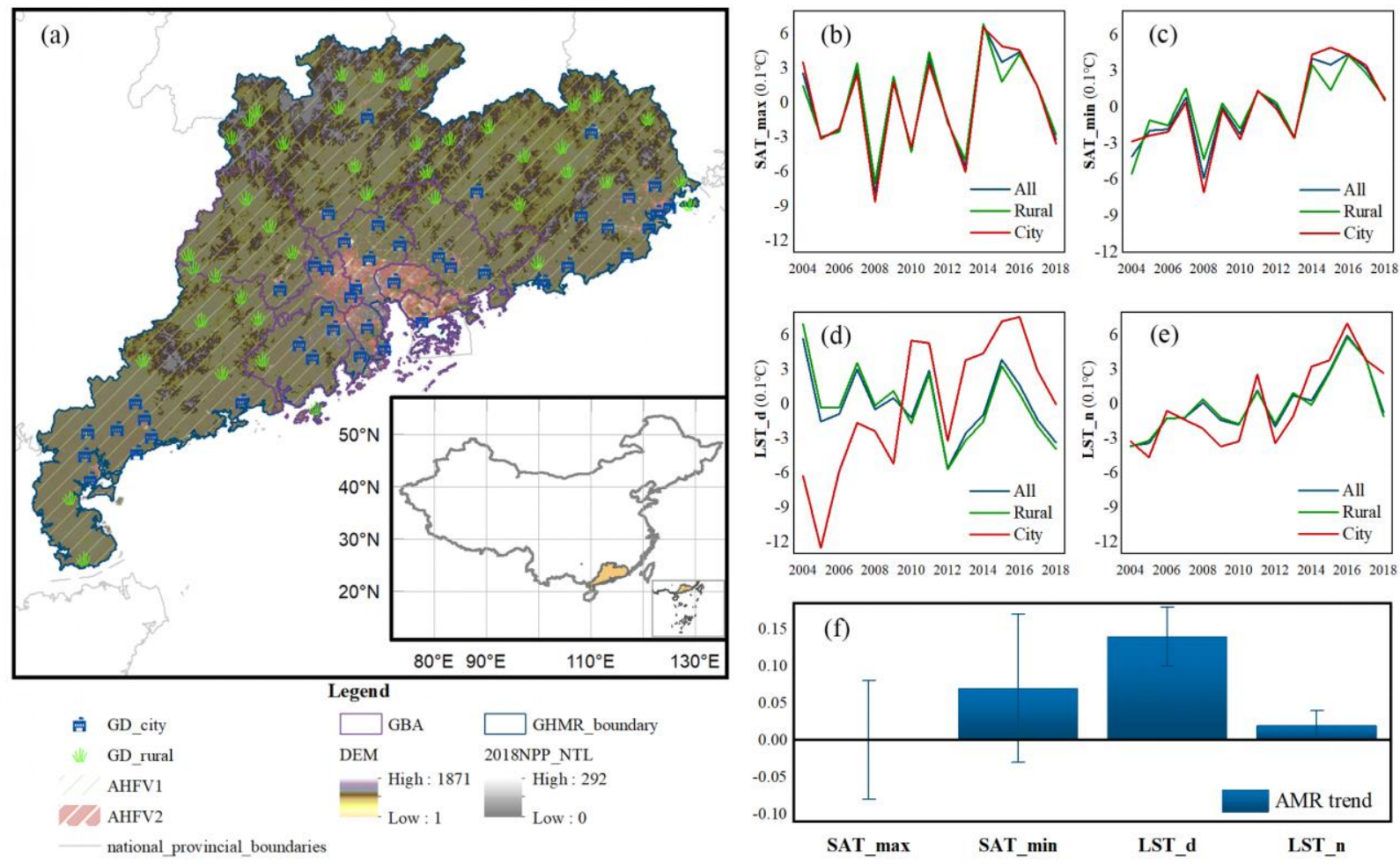

Fig.1 Impacts of urbanization on summer SAT and LST changes in the GHMR from 2004-2018. (a) Regional and observatory distribution, urban and non-urban divisions. (b-e) Comparison of regional mean variations of summer SAT max (b), SAT_min (c), LST_d (d) and LST_n (e), for the whole GHMR, in urban areas and in rural areas; (f) Contribution of urbanization to the trends of summer SAT and LST changes in GHMR and its significance (at the 5\% level)

\subsection{Analysis of modulation factors of urbanization warming}

Yang et al. (2020) adopted the RF machine learning method and concluded that the diurnal temperature range (DTR) in specific urban areas in the central part of the Yangtze River Delta Region was modulated by urban AHF emissions (see Texts S12 and Table S3 in the SI). Considering the relatively smaller sample size in this study, we used another analysis method - the PLSR to analyze modulation factors on average SAT and LST in GHMR from 2004 to 2018.

Figure 2 shows the results of the modulation factor analysis for GHMR of the mean Tmax (Fig. 2a-c), mean Tmin (Fig. 2d-f), mean daytime LST (Fig. 2g-i) and mean nighttime LST (Fig. 2j-l) in GHMR as a whole, in rural and urban areas, respectively. Overall, the regression fit performs better at nighttime than daytime (with a larger fitted $R^{2}$ ) for both SAT and LST, indicating different physical processes in controlling day and night temperatures. For the summer mean $T_{\max }$ over the whole GHMR (Fig. 2a-c), the coefficients' ranking in order of their weights (the horizontal bars at the right side of each panel) is as follows: LST_d, PRE, SSD, DEM, EVI,

This article is protected by copyright. All rights reserved. 
LST_n, and AHF. Although the ranking of the coefficients does not change much for rural and urban areas,the only three factors that reach statistical significance at the 5\% level are LST_d, PRE, and SSD. Besides, these factors have a low overall explained variance for summer SAT. For the mean $T_{\min }$ of GHMR in summer (Fig. $2 d-f)$, the total explained variance of all factors improved significantly, and the factors with larger weights in the coefficients are mainly LST_n, PRE, SSD, and LST_d. However, the factors that reach significance at the 5\% level are still mainly dominated by natural factors. Only the modulating factor AHF for the mean $T_{\min }$ in urban areas reaches the 5\% significance level, indicating that the nighttime LST in urban areas of GHMR is modulated to some extent by AHF emissions, which is also consistent with the previous study (Chao et al., 2020). For the modelling of day-and-night LST, the situation differs significantly compared to the SAT results: for the average diurnal LST of GHMR in summer (Fig 2g-i), the factors with the maximum coefficient weights are consistently EVI, PRE, and AHF, whether for the whole region, for rural areas or the urban areas, and all of them reach significance (at the 5\% level). For urban areas, the weight of AHF is the highest, i.e., indicating that AHF is the predominant driver of daytime LST in urban areas. For summer mean nighttime LST over the whole GHMR (Fig 2j-l), EVI becomes the most heavily weighted driver, but AHF also reaches significance at the 5\% level (see Table S6 in the SI).
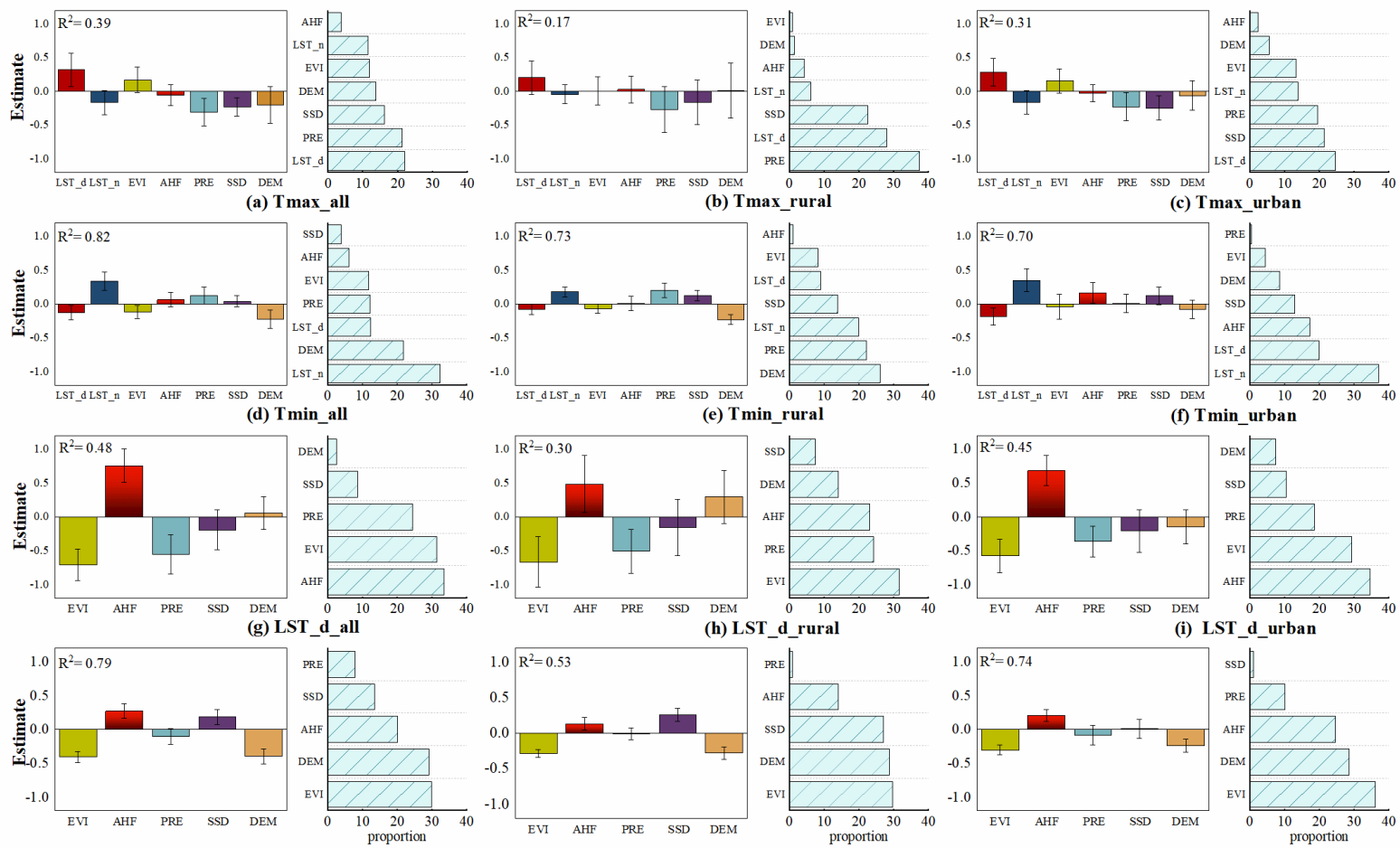

(j) LST_n_all

(k) LST_n_rural

(l) LST_n_urban

This article is protected by copyright. All rights reserved. 
Fig.2 Modulation factor analysis of mean summer Tmax (a-c), mean Tmin (d-f), mean daytime LST (g-i), and mean nighttime LST (j-1) in GHMR region, in urban areas and in rural areas. (Left: standardized coefficients of each factor and their significance (at the 5\% level); Right: comparison in the weight of each factor's coefficient)

\section{Discussion}

\subsection{Changes of vegetation greening and its possible links to urbanization warming}

The above analysis highlights the significant difference of the impact of urbanization on the SAT of GHMR during the past 40 years compared to that during the past 15 years. Fig.3 shows the spatial distribution of two vegetation indices (NDVI and EVI, see Figure S5 in the SI) and their temporal variation in the summer for GHMR, since the 1980s. Considering the data coverage period, two NDVI/EVI datasets (from GIMMS and MODIS, see Texts S10 and S13 in the SI) are used to describe the urbanization development characteristics of GHMR. Obviously, the average value of NVDI in the Greater Bay Area (GBA) (the most developed area in GHMR, Fig. 1a) is the lowest, indicating the highest urbanization development level in this region. Simultaneously, the urbanization development level in some areas in eastern and western Guangdong has also reached a certain scale but is much lower than that in the GBA. During the past 40 years, the average NDVI changes in GHMR show significant decreasing trends from 1982 to 1997, but a trend shift there after that. Therefore, we divided the data in our study region into two periods: 1982-2003 and 2004-2018, according to the temporal coverage of satellite-derived LST data. During the period of 1982-2003, in the whole GHMR region, except for only a few southern coastal (including the GBA area) areas showing a significant increasing trend of NDVI, most areas exhibited a significant decreasing trend or insignificant change. Moreover, as a whole, the regional average showed a slightly decreasing trend (but insignificant) during the period 1982-2003. In contrast, after 2004, the entire GHMR region showed a significant increasing trend of NDVI (i.e., a widespread greening) in summer. In terms of the regional average, both the NDVI derived from GIMMS (2004-2015) and that from MODIS (2004-2018) show a significant increasing trend (at the 5\% level). According to previous studies (Zhou et al., 2004; Peng et al., 2012; Oke et al., 2017), vegetation (NDVI) has a moderating effect on SAT warming, and the greening largely decreases daytime LST and slightly increases nighttime LST.

This article is protected by copyright. All rights reserved. 


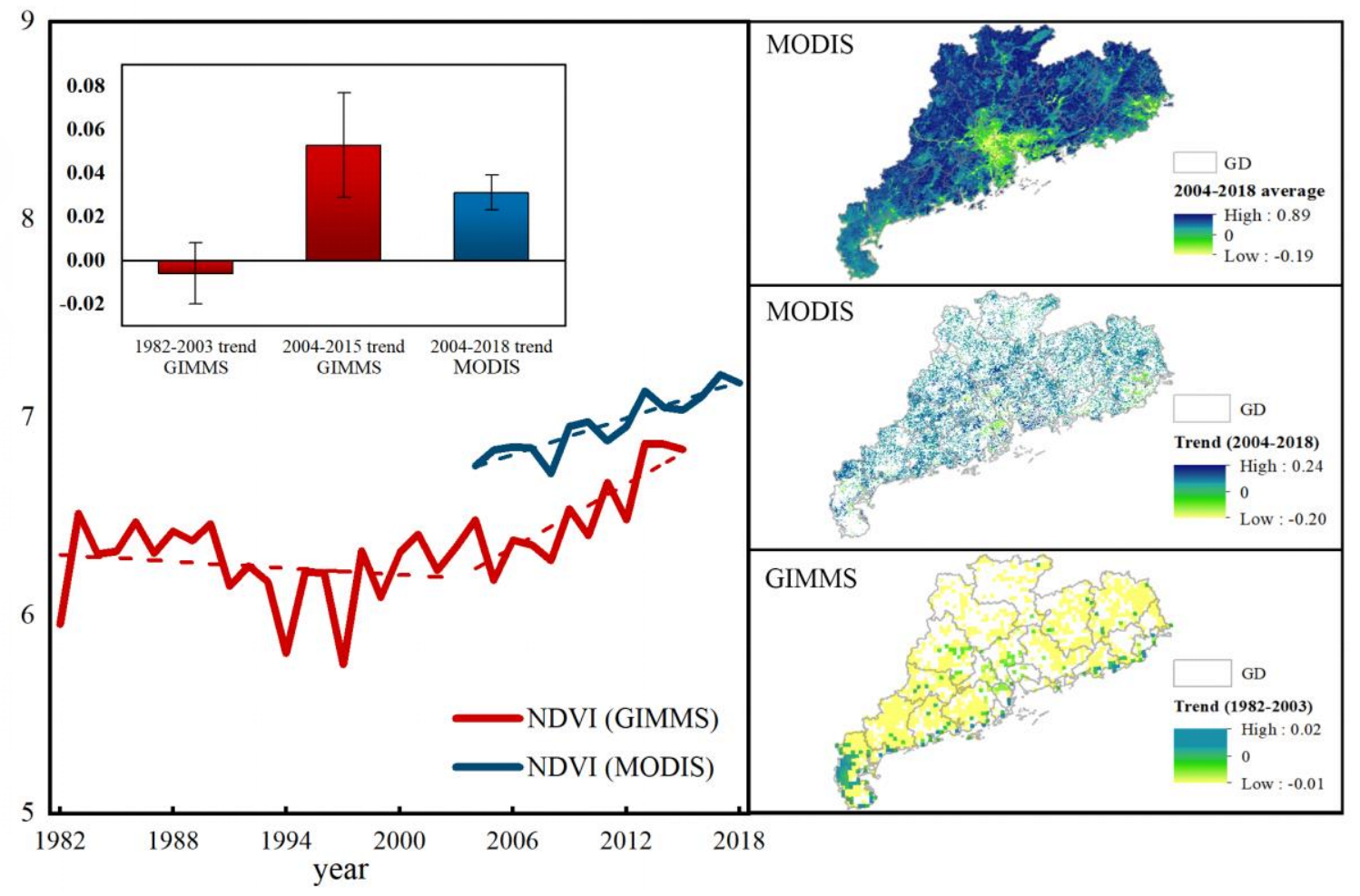

Fig.3 Changes in vegetation greenness index over the GHMR from 1982 to 2018. (Left: 1982-2015 NDVI (GIMMS) and 20032018 NDVI (MODIS) time series, linear trends, and their uncertainties (at the 5\% significance level); Top right: distribution of NDVI (MODIS) means for 2004-2018; Middle right: distribution of linear trends of NDVI (MODIS) for 2004-2018; Bottom right: distribution of NDVI (GIMMS) means for 1982-2003)

The widespread greening over the GHMR may be the direct and primary reason to explain why urbanization has no significant impact on the change in mean SAT in the study region during the period of 2004-2018. It is worth mentioning that urban areas have much less vegetation than rural areas and so urbanization has an overall warming effect on urban ground and air temperatures (Eliasson et al., 1996; Onishi et al., 2010; Peng et al., 2014). This warming effect is particularly strong on ground temperature during the daytime in summer (the LST is less affected by the clouds during the day than at night (see Figure S6 in the SI), when the ground temperature is usually much higher than the air temperature, and due to the differences in land surface properties, the urban ground has more heat storage and lower heat dissipation rate than rural areas (Eliasson et al., 1996; Oke et al., 2017). So we expect to see highly significant urbanization warming in daytime LST (Fig. 1f). However, the net temperature changes over the GHMR depends on the combination of the local warming effect associated with urbanization and the daytime cooling and nighttime warming effects associated with the large-scale greening. During the daytime, the opposite sign of the greening and urbanization effects over urban areas results in small

This article is protected by copyright. All rights reserved. 
or insignificant daytime and mean SAT changes, In contrast, the same sign of these two effects enhances the urbanization signal and results in a net warming SAT trend.

\subsection{Interrelationship of EVI and AHF with SAT/LST at local sites}

Both local EVI and AHF are indicative of the degree of urbanization development. The EVI/NDVI reflects the degree of vegetation greenness (or vegetation cover) of the land surface. With less vegetation in urban areas, the evaporative cooling of moisture evaporation and transpiration from plants is reduced, leading to an increase in SAT and LST over urban areas at low latitudes (the opposite effect is possible at higher latitudes) (Lee et al., 2011;Schulze et al., 2014). However, note that greenhouse gases such as $\mathrm{CO}_{2}$ also have a certain effect on vegetation and temperatures; in contrast, $\mathrm{AHF}$ is an additional local heat in urban areas, but there is a clear negative correlation between the two (AHF and EVI). Fig. 4 analyzes the regressions of both AHF and EVI with the corresponding Tmax, Tmin, DTR, LST_d, LST_n, and LST_d-n, respectively, at the local scale (5 km around 86 meteorological stations). Evidently, the $\mathrm{R}^{2}$ of the linear fitting of AHF and EVI for Tmax is small, indicating that an increase in AHF or a decrease in EVI does not lead to a significant increase in Tmax (Fig.4a). AHF and EVI improved the fitted $\mathrm{R}^{2}$ of Tmin, and there was a positive correlation between the increase in AHF and Tmin, while there was a negative correlation between the rise in EVI and Tmin (Fig. 4b). This indicates that although at the local scale the increase in AHF contributed to the warming of the mean Tmin, its contribution does not reach a significant level on the overall scale (Fig. 2d). In contrast, the decrease of EVI trend at the local scale contributes to the increase in Tmin, while in terms of overall contribution, the increase in EVI (Fig.3) is significantly correlated to the decrease in mean Tmin (Fig.2d). As a result, the increase in AHF and decrease in EVI favors the decrease in DTR (Fig.4c). On the contrary, whether the increase of LST_d, LST_n, and AHF or the decrease of EVI are all conducive to the rise of local surface temperature (Fig.4d, e), is an important issue, but this is more consistent with the situation of the whole region (Fig.2g, j) (the fitting effect is also better than SAT). However, unlike DTR, the correlation between EVI and AHF and LST_d-n (LST_d-LST_n) is not significant (Fig.4f). These results endorse the increase of vegetation enhanced the latent heat flux transfer between the land and the atmosphere, and the potential of greenery as an urban heat mitigation strategy (Chen et al., 2020b; Wong et al., 2021).

This article is protected by copyright. All rights reserved. 

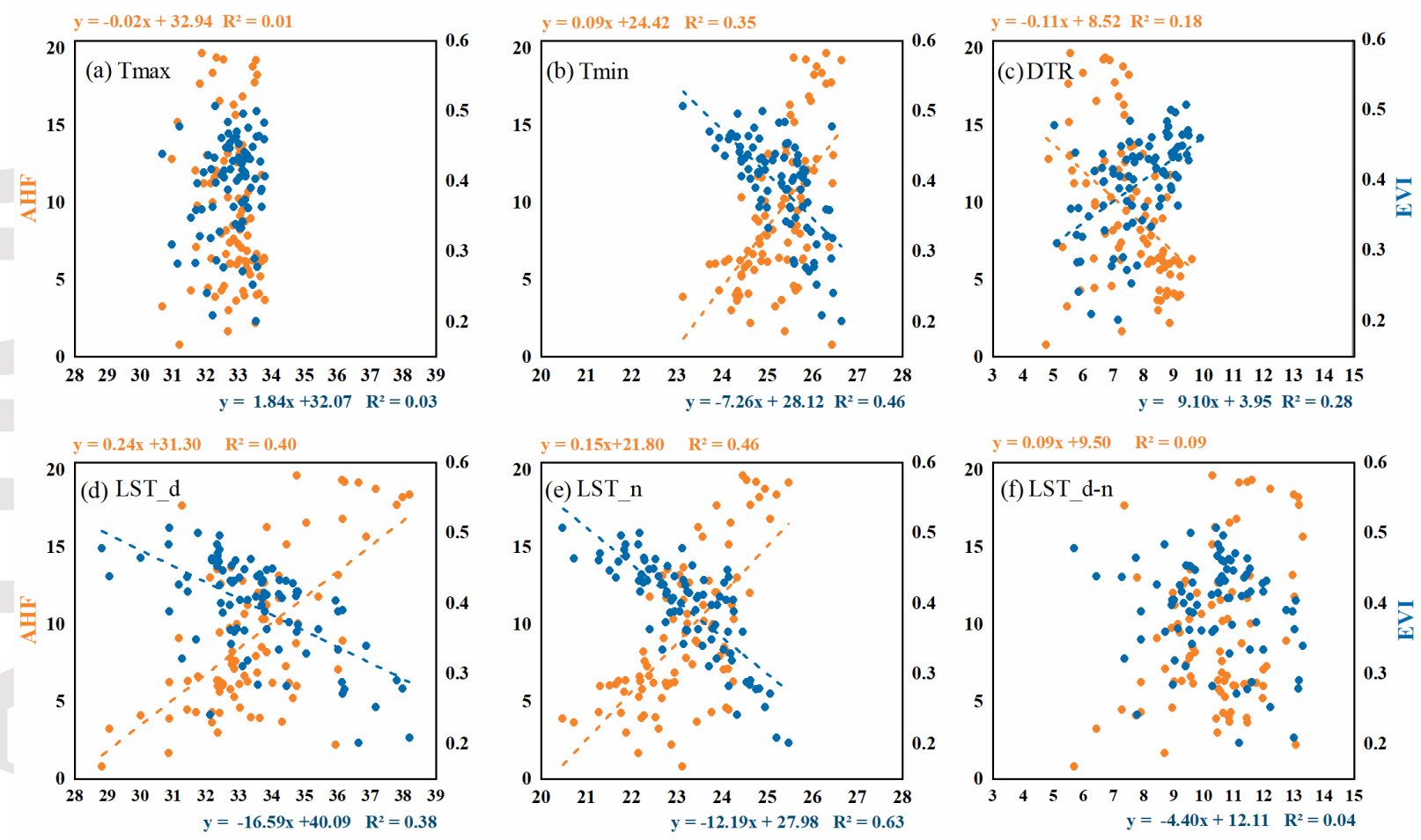

Fig.4 Map of the interrelationship of EVI and AHF distributions with SAT (Tmax, Tmin, DTR) and LST (LST_d, LST_n,

LST_d-n) at local sites (86 meteorological stations)

\section{Conclusions}

This paper analyzes the impact of urbanization on SAT and LST in the GHMR during different periods, then a PLSR model was established to analyze its driving factors. The main conclusions are as follows: In GHMR, the influence of urbanization on surface temperature is obviously different between the recent 40 years and the recent 15 years. From 1979 to 2018, urbanization contributed significantly to GHMR summer warming (at the 5\% significance level) (Chao et al., 2020), the significant increase in regional vegetation in 2004-2018 led to a decrease in its contribution to SAT warming, but at the same time urbanization contributed $0.14 \pm 0.04{ }^{\circ} \mathrm{C} / 10 \mathrm{a}$ during the day and $0.02 \pm 0.02{ }^{\circ} \mathrm{C} / 10 \mathrm{a}$ during the night, that is to say, urbanization has significantly warmed the LST of GHMR. Our analysis further indicates that extensive greening (EVI/NDVI) and AHF (two different indicators of urbanization) in the GHMR during this period had a limited effect on the SAT, and their contribution to the warming of LST was significant and substantial. It is also worth pointing out here that our conclusions are mainly based on the analysis of the LST retrieved under clear-sky conditions, which will lead to some uncertainties. The percentage of cloudy days leading to unavailability of LST data ranges only from 7\% (daytime) to $41 \%$ (nighttime) in summer in the GMHR region (see the Figure S6 in the SI).

This article is protected by copyright. All rights reserved. 
In summary, our findings have important implications for understanding the influences of human activities on regional climate and environmental change for other regions of the world that experience various urbanization. Its findings can also provide a frame of reference for decision-making in response to urban climate change at a larger scale. Our analysis results demonstrate that it is also essential to strengthen the control of additional warming effects caused by urbanization, and deal with global warming caused by greenhouse gases. In terms of reducing the additional warming of SAT by urbanization, increasing the regional EVI (NDVI) has a significant impact (especially for reducing the nighttime SAT) on it. In contrast, in order to mitigate the surface warming caused by urbanization, it is essential to increase EVI (NDVI) and reduce anthropogenic heat emission fluxes in parallel. Our results provide new methods for quantitative evaluation of different urbanization warming and how decision-making might mitigate the effects at regional scales.

\section{Acknowledgments}

We thank the China National Meteorological Information Center (NMIC) for providing the observational data. The MODIS data are provided by NASA. The nighttime light (NTL) data are obtained from NOAA. The Digital Elevation Model (DEM) produced by NASA originally. This article uses the revised version 4.1 of the CGIAR Consortium for Spatial Information (CGIAR-CSI), and the data are downloaded from the Chinese Academy of Sciences (CAS). We thank Dr. Bing Chen, School of Earth Sciences, Yunnan University, China, for providing the AHF dataset for the GHMR from 2004-2018. This study is supported by the National Key R\&D Programs of China (Grants 2018YFC1507705 and 2017YFC1502301) and the Natural Science Foundation of China (Grant 41975105).

\section{Data Availability Statement}

For the LST (MYD11A2), the vegetation indices (MYD13A3), and the land-use data (MCD12Q1) are available from the NASA (at https://ladsweb.modaps.eosdis.nasa.gov/search/). GIMMS vegetation index dataset is available for free on (http://iridl.ldeo.columbia.edu/SOURCES/.NASA/.ARC/.ECOCAST/. GIMMS/.NDVI3g/.v1p0/). The Nighttime light (NTL) data is downloaded from the NOAA National Geographic Data Center (https://www.ngdc.noaa.gov/eog/download.html). The Observational meteorological stations data

This article is protected by copyright. All rights reserved. 
(Tmax, Tmin, PRE, SSD), DEM data and the AHF data for the work in this paper can be downloaded from this site (https://doi.org/10.6084/m9.figshare.14955711.v2).

\section{References}

Breiman, L. (2001). Random forests. Machine Learning. 45,5-32. doi:10.1023/A:1010933404324

Chaisson, E. J., (2008). Long-term global heating from energy usage. EOS, Transactions American Geophysical Union, 89,253260. doi:10.1029/2008EO280001

Chao, L.Y., Huang, B.Y., Yang, Y.J., Jones, P.D., Cheng, J.Y., Yang, Y., \& Li, Q. (2020). An assessment of the urbanization contribution to the warming in the Guangdong-Hong Kong-Macao Region (GHMR). Geophysical Research Letters, 47, e2020GL089152. doi: 10.1029/2020GL089152

Chen, B., Dong, L., Shi, G. Y., Li, L. J., \& Chen, L.F. (2014). Anthropogenic Heat Release: Estimation of Global Distribution and Possible Climate Effect. Journal of the Meteorological Society of Japan, 92A, 157-165. doi:10.2151/jmsj.2014-A10

Chen, C., Li, D., Li, Y., Piao, S. L., Wang, X. H., Huang, M. Y., et al. (2020b). Biophysical impacts of Earth greening largely controlled by aerodynamic resistance. Science Advances, 6, eabb1981. doi:0.1126/sciadv.abb1981

Chen, B., Li, D., Liu, X., Shi, G. Y., Chen, L., Nakajima, T., Habib,A. (2016). Exploring the Possible Effect of Anthropogenic Heat Release Due to Global Energy Consumption Upon Global Climate: A Climate Model Study. International Journal of Climatology, 36,4790-4796. doi:10.1002/joc.4669

Chen, B., \& Shi, G. Y. (2012a). Estimation of the distribution of global anthropogenic heat flux. Atmospheric and Oceanic Science Letters, 5, 108-112. doi:10.1080/16742834.2012.11446974

Chen, B., Shi, G. Y., Wang, B., Zhao, J. Q., \& Tan, S.C. (2012b). Estimation of the Anthropogenic Heat release Distribution in China from 1992 to 2009. Acta Meteorologica Sinica, 26, 507-515. doi:10.1007/s13351-012-0409-y

Chen, B., Wu, C., Liu, X., Chen, L., Wu, J., Yang, H., et al. (2019). Seasonal climatic effects and feedbacks of anthropogenic heat release due to global energy consumption with CAM5. Climate Dynamics, 52, 6377-6390. doi:10.1007/s00382-018$4528-1$

Chen, G. W., Wang, D. Y., Wang, Q., Li, Y. G., Wang, X. M., Hang, J., et al. (2020a). Scaled outdoor experimental studies of urban thermal environment in street canyon models with various aspect ratios and thermal storage. Science of The Total Environment, 726, 138147. doi:10.1016/j.scitotenv.2020.138147

Dietterich, T. G. (2000). An experimental comparison of three methods for constructing ensembles of decision trees: bagging, boosting, and randomization. Machine Learning, 40, 139-157. doi:10.1023/A:1007607513941

Didan, K. (2015). MYD13A3 MODIS/Aqua Vegetation Indices Monthly L3 Global 1km SIN Grid V006. NASA EOSDIS Land Processes DAAC. doi:10.5067/MODIS/MYD13A3.006

Eliasson, I. (1996). Urban nocturnal temperatures, street geometry and land use. Atmospheric Environment. 30, $379-392$. doi:10.1016/1352-2310(95)00033-X

This article is protected by copyright. All rights reserved. 
Friedl, M., Sulla-Menashe, D. (2019). MCD12Q1 MODIS/Terra+Aqua Land Cover Type Yearly L3 Global 500m SIN Grid V006. NASA EOSDIS Land Processes DAAC. doi:10.5067/MODIS/MCD12Q1.006

Gallo, P., McNab, A. L., Karl, T. R., Brown, J. F., Hood, J. J., \& Tarpleye, J. D. (1993). The Use of NOAA AVHRR Data for Assessment of the Urban Heat Island Effect. Journal of Applied Meteorology and Climatology, 32, 899-908. doi:10.1175/1520-0450(1993)032<0899:TUONAD>2.0.CO;2

Hartmann, D. L., Tank, A. K., Rusticucci, M., Alexander, L. V., Brönnimann, S., Charabi, Y. A. R., et al. (2013). Observations: Atmosphere and surface. Cambridge: Cambridge University Press. doi:10.1017/CBO9781107415324.008

Huete, R., \& Liu, H. (1994). An error and sensitivity analysis of the atmospheric- and soil-correcting variants of the NDVI for the MODIS-EOS. IEEE Transactions on Geoscience and Remote Sensing, 32,897-905. doi:10.1109/36.298018

Huang, F., Zhan, W. F., Wang, Z. H., Wang, K. C., Chen, J. M., Liu, Y. X., et al. (2017). Positive or negative? Urbanization $\square$ induced variations in diurnal skin $\square$ surface temperature range detected using satellite data. Journal of Geophysical Research: Atmospheres, 122(24), 13229-13244. doi:10.1002/2017JD027021

Jones, P. D., Groisman, P. Y., Coughlan, M., Plummer, N., Wang, W. Y., Karl, T. R. (1990). Assessment of urbanization effects in time series of surface air temperature over land. Nature, 347(6289):169-172. doi:10.1038/347169a0

Jones, P. D., Lister, D. H., Li, Q. X. (2008). Urbanization effects in large-scale temperature records, with an emphasis on China. Journal of Geophysical Research: Atmospheres, 113(D16). doi:10.1029/2008JD009916

Jiang, S. J., Lee, X. H., Wang, J. K., \& Wang, K. C. (2019). Amplified urban heat islands during heat wave periods. Journal of Geophysical Research: Atmospheres, 124(14), 7797-7812. doi:10.1029/2018JD030230

Li, Q. X. (2020b). Statistical modeling experiment of land precipitation variations since the start of the 20th century with external forcing factors. Chinese Science Bulletin, 65(21), 2266-2278, in Chinese. doi:10.1360/TB-2020-0305

Li, Q. X. \& Dong, W. J. (2009). Detection and Adjustment of Undocumented Discontinuities in Chinese Temperature Series Using a Composite Approach. Advances in Atmospheric Sciences, 26(1):143-153. doi: 10.1007/s00376-009-0143-8

Li, Q. X., Dong, W. J., \& Jones, P. (2020a). Continental Scale Surface Air Temperature Variations: Experience Derived from Chinese Region, Earth-Science Reviews, 200, 998. doi:10.1016/j.earscirev.2019.102998

Lee, X. H., Goulden, M. L., Hollinger, D. Y., Barr, A., Black, T. A., Bohrer, G., et al. (2011). Observed increase in local cooling effect of deforestation at higher latitudes. Nature, 479, 384-387. doi:10.1038/nature10588

Li, Q. X., Huang, J. Y., Jiang, Z. H., Zhou, L. M., Chu, P., \& Hu, K.X. (2014). Detection of Urbanization Signals in Extreme Winter Minimum Temperature changes over Northern China. Climatic Change, 122, 595-608. doi:10.1007/s10584-013$1013-\mathrm{z}$

Li, Q. X., Liu, X. N., Zhang, H. Z., Thomas,C. P.. \& David, R. E. (2004b). Detecting and adjusting temporal inhomogeneity in Chinese mean surface air temperature data. Advances in Atmospheric Sciences, 21(2), 260-268. doi: 10.1007/BF02915712

Li, Y. B., Shi, T., Yang, Y. J., Wu, B. W., Wang, L. B., Shi, C. E., et al. (2015). Satellite-based Investigation and Evaluation of the Observational Environment of Meteorological Stations in Anhui Province, China. Pure and Applied Geophysics, 172 , 1735-1749. doi:10.1007/s00024-014-1011-8

This article is protected by copyright. All rights reserved. 
Liaw, A., \& Wiener, M. (2002). Classification and Regression by randomForest. R News, 2(3), 18--22.

Li, Q. X., Zhang, H., Liu, X., Huang, J. (2004a). Urban heat island effect on annual mean temperature during the last 50 years in China. Theoretical and Applied Climatology, 79(3-4):165-174. doi:10.1007/s00704-004-0065-4

Li, Q. X., Zhang L., Xu W., et al. (2017). Comparisons of time series of annual mean surface air temperature for China since the 1900s: Observation, Model simulation and extended reanalysis. Bulletin of the American Meteorological Society, 98 (4):699-711. doi: 10.1175/BAMS-D-16-0092

Manoli, G., Fatichi, S., Schläpfer, M., Yu, K. L., Crowther, T. W., Meili, N., et al. (2019). Magnitude of Urban Heat Islands Largely Explained by Climate and Population. Nature, 573, 55-60. doi:10.1038/s41586-019-1512-9

Mevik, B., Wehrens. R., Liland, K. H., Hiemstra, P. (2020). pls: Partial Least Squares and Principal Component Regression. R package version 2.7-3. https://CRAN.R-project.org/package=pls

Onishi, A., Cao, X., Ito, T., Shi, F., Imura, H. (2010). Evaluating the potential for urban heat-island mitigation by greening parking lots. Urban Forestry \& Urban Greening, 9(4), 323-332. doi:10.1016/j.ufug.2010.06.002

Oke, T. R., Mills, G., Christen, A., \& Voogt, J. (2017). Urban Climates. Cambridge: Cambridge University Press.

Peterson, T. (2003). Assessment of Urban Versus Rural In Situ Surface Temperatures in the Contiguous United States: No Difference Found. Journal of Climate, 16(18), 2941-2959. doi: 10.1175/1520-0442(2003)016<2941:AOUVRI> 2.0.CO;2

Parker, D. E. (2004). Climate: Large-scale warming is not urban. Nature, 432(7015), 290-290. doi:10.1038/432290a

Peng, S. S., Piao, S. L., Ciais, P., Friedlingstein, P., Ottle, C., Bréon, F. M., et al. (2012). Surface urban heat island across 419 global big cities. Environmental Science \& Technology, 46, 696-703. doi: 10.1021/es2030438

Peng, S. S., Piao, S. L., Zeng, Z. Z., Ciais, P., Zhou, L. M., Li, L. Z. X., et al. (2014). Afforestation in China cools local land surface temperature. Proceedings of the National Academy of Sciences of the United States of America, 111(8), 2915-2919 . doi:10.1073/pnas.1315126111

Pinzon, J. E., \& Tucker, C. J. (2014). A Non-Stationary 1981-2012 AVHRR NDVI3g Time Series. Remote Sensing, 6(8), 69296960. doi:10.3390/rs6086929

Qian, C. (2015). On trend estimation and significance testing for non-Gaussian and serially dependent data: quantifying the urbanization effect on trends in hot extremes in the megacity of Shanghai. Climate Dynamics, 47(1-2), 329-344. doi: $10.1007 / \mathrm{s} 00382-015-2838-0$

Qian, G. Z., Li, Q. X., Li, C., Li, H. Y., Wang, X. L., Dong, W. J ., et al. (2021). A novel Statistical Decomposition of the Historical Change in Global Mean Surface Temperature. Environmental Research Letters, 16, 054057. doi:10.1088/17489326/abea34

Rao, P. K. (1972). Remote Sensing of Urban Heat Islands from an Environmental Satellite. Bulletin of the American Meteorological Society, 53, 647-648. doi:10.1016/j.ecocom.2009.02.002

Rao, Y. H., Liang, S. L., Wang, D. D., Yu, Y. Y., Song, Z., Zhou, Y., et al. (2019). Estimating Daily Average Surface Air Temperature Using Satellite land surface temperature and top-of-atmosphere radiation products over the Tibetan Plateau. Remote Sensing of Environment, 234, 111462. doi:10.1016/j.rse.2019.111462

This article is protected by copyright. All rights reserved. 
Reuter, H. I., Nelson, A., Jarvis, A. (2007). An evaluation of void filling interpolation methods for SRTM data. International Journal of Geographical Information Science. 21(9), 983-1008. doi:10.1080/13658810601169899

Roth, M., Oke, T. R., \& Emery, W. J. (1989). Satellite-derived urban heat islands from three coastal cities and the utilization of such data in urban climatology. International Journal of Remote Sensing, 10(11), 1699-1720. doi:10.1080/01431168908904002

Ren, Y., \& Ren, G. Y. (2011). A Remote-Sensing Method of Selecting Reference Stations for Evaluating Urbanization Effect on Surface Air Temperature Trends. Journal of Climate, 24(13), 3179-3189. doi:10.1175/2010JCLI3658.1

Streutker, D. R. (2002). A Remote Sensing Study of the Urban Heat Island of Houston, Texas. International Journal of Remote Sensing, 23(13), 2595-2608. doi:10.1080/01431160110115023

Schulze, H., \& Langenberg, H. (2014). Urban heat. Nature Geoscience, 7, 553. doi:10.1038/ngeo2219

Schwarz, N., Lautenbach, S., \& Seppelt, R. (2011). Exploring Indicators for Quantifying Surface Urban Heat Islands of European Cities with MODIS Land Surface Temperatures. Remote Sensing of Environment, 115(12), 3175-3186. doi:10.1016/j.rse.2011.07.003

Wold, S., Albano, C., \& Dun, M. (1983). Pattern Regression Finding and Using Regularities in Multivariate Data. London: Analysis Applied Science Publication.

Wang, X. L., Feng, Y. (2010). RHtestsV3 User Manual, User Manual.doc. Available online at http://cccma.seos.uvic.ca/ETCCDMI/RHtest/RHtestsV3

Wang, F., Ge, Q., Wang, S., Li, Q. X., Jones, P. D. (2015). A New Estimation of Urbanization's Contribution to the Warming Trend in China. Journal of Climate, 28(22), 8923-8938. doi:10.1175/JCLI-D-14-00427.1

Wan, Z., Hook, S., Hulley, G. (2015). MYD11A2 MODIS/Aqua Land Surface Temperature/Emissivity 8-Day L3 Global 1km SIN Grid V006. NASA EOSDIS Land Processes DAAC. doi:10.5067/MODIS/MYD11A2.006.

Wang, K. C., Jiang, S. J., Wang, J. k., Zhou, C. L., Wang, X. Y., Lee, X. (2017). Comparing the Diurnal and Seasonal Variabilities of Atmospheric and Surface Urban Heat Islands Based on the Beijing Urban Meteorological Network. Journal of Geophysical Research: Atmospheres, 122(4), 2131-2154. doi:10.1002/2016JD025304

Watkins, R., Palmer, J., \& Kolokotroni, M. (2007). Increased Temperature and Intensification of the Urban Heat Island: Implications for Human Comfort and Urban Design. Built Environment, 33, 85-96. doi:10.2148/benv.33.1.85

Wang, X., Rafa, M., Moyer, J. D., Li, J., Scheer, J., \& Sutton, P. C. (2019). Estimation and Mapping of Sub-National GDP in Uganda Using NPP-VIIRS Imagery. Remote Sensing, 11(2). doi:10.20944/preprints201811.0520.v1

Wong, N. H., Tan, C. L., Kolokotsa, D. D., \& Takebayashi, H. (2021). Greenery as a mitigation and adaptation strategy to urban heat. Nature Reviews Earth \& Environment, 2,166-181. doi:10.1038/s43017-020-00129-5

Xu, W., Li, Q. X., Wang, X. L., Yang, S., Cao, L. J., Feng, Y. (2013). Homogenization of Chinese daily surface air temperatures and analysis of trends in the extreme temperature indices. Journal of Geophysical Research: Atmospheres, 118(17), 97089720. doi:10.1002/jgrd.50791

Xie, Y., Weng, Q., \& Fu, P. (2019). Temporal variations of artificial nighttime lights and their implications for urbanization in

This article is protected by copyright. All rights reserved. 
the conterminous United States, 2013-2017. Remote Sensing of Environment,160-174. doi:10.1016/j.rse.2019.03.008

Yang, X., Hou, Y., \& Chen, B. (2011). Observed surface warming induced by urbanization in east China. Journal of Geophysical Research, 116(D14113). doi:10.1029/2010JD015452

Yan, Z., Li, Z., Li, Q., \& Jones, P.D. (2009). Effects of site change and urbanisation in the Beijing temperature series $1977-$ 2006. International Journal of Climatology, 30(8), 1226-1234. doi:10.1002/joc.1971

Yang, W. M., Luan, Y. B., Liu, X. L., Yu, X. Y., Miao, L. J., \& Cui, X.F. (2017). A new global anthropogenic heat estimation based on high-resolution nighttime light data. Scientific Data, 4, 170116. doi: 10.1038/sdata.2017.116

Yao, R., Wang, L.C., Huang, X., Niu, Z. G., Liu, F. F., Wang, Q. (2017). Temporal Trends of Surface Urban Heat Islands and Associated Determinants in Major Chinese Cities. Science of The Total Environment, 609, 742-754. doi:10.1016/j.scitotenv.2017.07.217

Yang, Y. J., Wu, B. W., Shi, C. E., Zhang, J. H., Y. Li, Tang, W. A., et al. (2013). Impacts of Urbanization and Station-relocation on Surface Air Temperature Series in Anhui Province, China. Pure and Applied Geophysics, 170, 1969-1984. doi:10.1007/s00024-012-0619-9

Yang, Y. J., Zhang, M. Y., Li, Q. X., Chen, B., Gao, Z. Q., Ning, G. C., et al. (2020). Modulations of Surface Thermal Environment and Agricultural Activity on Intraseasonal Variations of Summer Diurnal Temperature Range in the Yangtze River Delta of China. Science of The Total Environment, 736, 139445. doi:10.1016/j.scitotenv.2020.139445

Zhou, L.M., Dickinson, R. E.,Tian, Y. H., Fang, J. Y., Li, Q. X., Kaufmann, R. K.,Tucker, C. J., \&Myneni, R. B. (2004). Evidence for a significant urbanization effect on climate in China. Proceedings of the National Academy of Sciences of the United States of America, 101(26), 9540-9544. doi:10.1073/pnas.0400357101

Zhao, L., Lee, X. H., Smith, R. B., \& Oleson, K. (2014). Strong Contributions of Local Background Climate to Urban Heat Islands. Nature, 511, 216-219. doi:10.1038/nature13462

This article is protected by copyright. All rights reserved. 